\title{
UK Renal Registry 14th Annual Report: Chapter 5 Demography of the UK Paediatric Renal Replacement Therapy population in 2010
}

\author{
Rishi Pruthi ${ }^{a}$, Manish D Sinha ${ }^{b}$, Anna Casula $^{a}$, Yincent Tse ${ }^{c}$, Heather Maxwell $^{d}$, \\ Catherine $\mathrm{O}^{\prime}$ Brien $^{\mathrm{e}}$, Malcolm Lewis ${ }^{\mathrm{f}}$, Carol Inward ${ }^{\mathrm{g}}$ \\ aUK Renal Registry, Bristol, UK; ${ }^{b}$ Evelina Childrens Hospital, London, UK; ${ }^{c}$ Royal Victoria Infirmary, Newcastle, UK; \\ ${ }^{d}$ Royal Hospital for Sick Children (Yorkhill), Glasgow, UK; 'Birmingham Children's Hospital, Birmingham, UK; \\ ${ }^{f}$ Manchester Children's Hospital, Manchester, UK; ${ }^{9}$ Bristol Royal Hospital for Children, Bristol, UK
}

\section{Key Words}

Aetiology · Children · Demography · End stage renal disease

- Established renal failure - Incidence · Prevalence - Ethnicity

- Renal replacement therapy

\begin{abstract}
Aims: To describe the demographics of the paediatric RRT population under the age of 16 years in the UK and to analyse changes in demography with time. Methods: Data were collected from all 13 paediatric renal centres within the UK. A series of cross-sectional and longitudinal analyses were performed to describe the demographics of prevalent paediatric RRT patients. Results: A total of 870 children and young people under 18 with ERF were receiving treatment at paediatric nephrology centres in 2010. At the census
\end{abstract}

date, $76.7 \%$ had a functioning transplant, $14.3 \%$ were receiving peritoneal dialysis (PD) and $9.0 \%$ were receiving haemodialysis (HD). In patients aged $<16$ years the prevalence of ERF was 59.3 pmarp and the incidence 8.1 pmarp. Analysis of trends over the last 15 years shows that both incidence and prevalence are increasing with the most marked increases in children aged 12-16 years and in ethnic minority groups. A third of the patients have one or more reported comorbidities. At transfer to adult services, $84.9 \%$ of patients had a functioning renal transplant. Conclusions: The data provided in this report show increasing trends over 15 years in the incidence and prevalence of established renal failure. This is important for the planning of the provision of care for children needing renal replacement therapy. The inclusion this year of an analysis of the patients transferring to adult services may assist in developing care pathways for this vulnerable group.

$\begin{array}{ll}\text { KARGER } & \text { C 2012 S. Karger AG, Basel } \\ \text { Fax +41 61 306 1234 } & \text { 1160-2110/12/1205-0093\$38.00/0 } \\ \begin{array}{l}\text { E-Mail karger@karger.ch } \\ \text { www.karger.com }\end{array} & \begin{array}{l}\text { Accessible online at: } \\ \text { www.karger.com/nec }\end{array}\end{array}$

Carol Inward

UK Renal Registry, Southmead Hospital, Southmead Road, Bristol, BS10 5NB, UK

Email: renalregistry@renalregistry.nhs.uk 


\section{Introduction}

Established renal failure (ERF) requiring renal replacement therapy (RRT) is a rare but significant cause of long term morbidity and mortality during childhood, with specialist care being provided in 13 paediatric nephrology centres throughout the UK. All centres are equipped to provide peritoneal dialysis and haemodialysis, with ten centres also undertaking transplantation for children. In the United Kingdom (UK), prevalence rates of treated ERF in children aged under 16 have risen steadily over the last 15 years to 65 per million age related population (pmarp) in 2009 [1]. This increase in prevalence is a consequence of improved survival of children across the paediatric age range as a result of advances in the delivery of care with more effective dialysis, improved nutrition and the availability of better immunosuppressive medications following renal transplantation. Incidence rates for ERF have also shown an increasing trend during this time period rising to 9.3 pmarp in 2009 [1].

The objectives of this report are:

(i) To describe the prevalence, incidence, causes of ERF and modality of treatment of children on RRT in the UK on 31st December 2010 and

(ii) To describe trends of the same over the past 15 years.

\section{Methods}

Data collection took place across the 13 paediatric nephrology centres in the UK that provided care to all children on RRT in 2010. As previously, most centres submitted data electronically to the UK Renal Registry (UKRR) with only four centres submitting data using paper-based data returns. These data items were then manually entered into the current paediatric UKRR database. Southampton, Newcastle and Manchester were only able to provide a limited electronic dataset this year due to a combination of technical difficulties and limited resources.

In this report, patient groups are described as follows: patients who were receiving RRT on the 31st December 2010 are the 'prevalent' group; patients who started RRT between 1st January and 31st December 2010 are the 'incident' group; and patients that started RRT in the periods of 1996-2000, 2001-2005 and 2006-2010 are the '5 year' groups.

The populations used to calculate the incidence and prevalence rates were obtained from the Office for National Statistics (ONS) [2]. The mid-2010 population estimate produced by the ONS, based on the 2001 Census, was used for calculating the incident and prevalent group rates and the 2001 Census data was used for the 1996-2000, 2001-2005 and 2006-2010 '5 year' groups.

Statistical analyses were performed using SAS 9.2, with group analyses using Fischer's exact test and median analyses using Kruskal-Wallis test.

\section{Results}

\section{Accuracy and completeness of data returns}

This year a significant amount of effort has been put into improving the overall accuracy of the entire paediatric dataset by clinical teams, data managers and statisticians. Problems identified in this process pertained largely to some patients being incorrectly registered as having started RRT whilst some patients were found to be duplicates within the prevalent RRT cohort (identified by combining the British Association of Paediatric Nephrology (BAPN) database and National Care Records) leading to historical over-estimation of prevalence rates. Subsequent corrections have undoubtedly led to achieving a more accurate dataset this year with more reliable analyses and conclusions. As for data returns the procedures for data collection and processing are still evolving but there was good completion of the core data items from most centres as shown in table 5.1 .

The UK paediatric prevalent ERF population in 2010

A total of 870 children and young people under 18 with ERF were receiving treatment at paediatric nephrology centres in 2010 . At the census date, $76.7 \%$ had a functioning transplant, $14.3 \%$ were receiving peritoneal dialysis (PD) and 9\% were receiving haemodialysis (HD).

Patients aged $16-18$ years may receive their medical care either in a paediatric or in an adult nephrology centre. As data was incomplete for the 16-18 year old adolescent patients they have been excluded from the majority of subsequent analyses (particularly when describing incidence and prevalence rates) so as to avoid misrepresentation. This report therefore presents data largely relating to patients less than 16 years of age only.

There were 688 children under 16 years of age receiving RRT in the UK in 2010. Table 5.2 shows the number of patients receiving RRT by age groups and gender plus rate of RRT pmarp. The prevalence of RRT increased with age and was higher in males across all age groups. The reported prevalence rate of 59.3 pmarp in under 
Table 5.1. Data completeness for paediatric prevalent ERF population in 2010

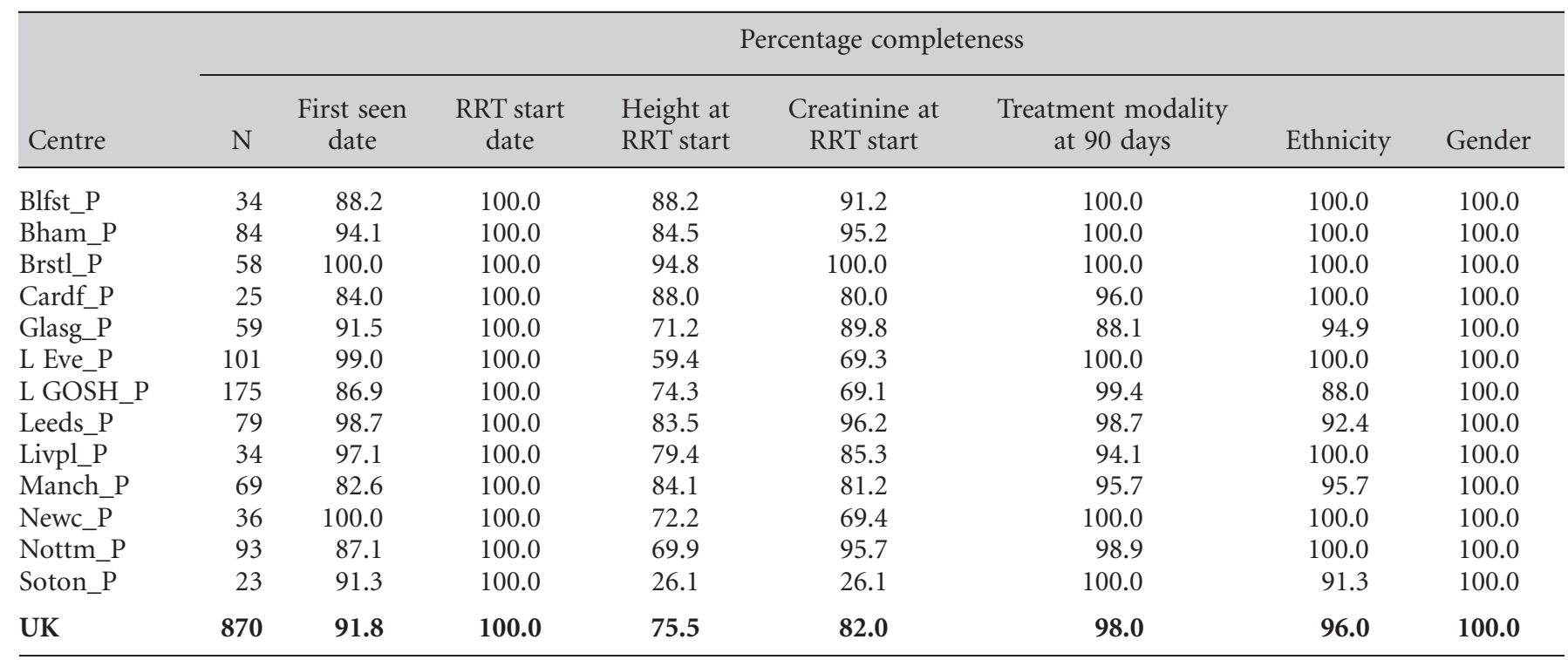

Table 5.2. UK paediatric prevalent ERF population in 2010 , by age group and gender

\begin{tabular}{|c|c|c|c|c|c|c|c|}
\hline \multirow[b]{2}{*}{ Age group } & \multicolumn{2}{|c|}{ All patients } & \multicolumn{2}{|c|}{ Males } & \multicolumn{2}{|c|}{ Females } & \multirow[b]{2}{*}{ Ratio $\mathrm{M}: \mathrm{F}$} \\
\hline & $\mathrm{N}$ & pmarp & $\mathrm{N}$ & pmarp & $\mathrm{N}$ & pmarp & \\
\hline $2-3.99$ years & 48 & 31.1 & 27 & 34.1 & 21 & 27.9 & 1.2 \\
\hline $4-7.99$ years & 131 & 46.0 & 86 & 59.0 & 45 & 32.4 & 1.8 \\
\hline $8-11.99$ years & 174 & 64.0 & 105 & 75.6 & 69 & 51.8 & 1.5 \\
\hline Under 16 years & 688 & 59.3 & 412 & 69.3 & 276 & 48.7 & 1.4 \\
\hline
\end{tabular}

pmarp - per million age related population

16 year olds was lower than 65 pmarp reported in the 2009 cohort because of the improved accuracy in patient identification.

Table 5.3 shows the ethnic origin of RRT patients and their prevalence rates. Increasing prevalence pmarp was observed with increasing age in all ethnic groups. Children from ethnic minorities displayed higher prevalent rates of RRT when compared with White children, with South Asian children displaying the highest prevalence rates.

Table 5.3. UK paediatric prevalent ERF population by age and ethnic group in $2010^{*}$

\begin{tabular}{|c|c|c|c|c|c|c|}
\hline \multirow[b]{2}{*}{ Age group } & \multicolumn{2}{|c|}{ White } & \multicolumn{2}{|c|}{ South Asian } & \multicolumn{2}{|c|}{ Black } \\
\hline & $\mathrm{N}$ & pmarp & $\mathrm{N}$ & pmarp & $\mathrm{N}$ & pmarp \\
\hline 0-3.99 years & 48 & 18.6 & 10 & 47.4 & 1 & 11.9 \\
\hline 4-7.99 years & 95 & 39.7 & 22 & 112.8 & 3 & 38.5 \\
\hline $8-11.99$ years & 131 & 51.2 & 21 & 100.7 & 8 & 95.9 \\
\hline $12-15.99$ years & 227 & 84.3 & 43 & 195.8 & 11 & 125.2 \\
\hline Under 16 years & 501 & 49.0 & 96 & 115.1 & 23 & 68.9 \\
\hline
\end{tabular}

pmarp - per million age related population

* ethnicity data missing in 29 children who are not included in this table 


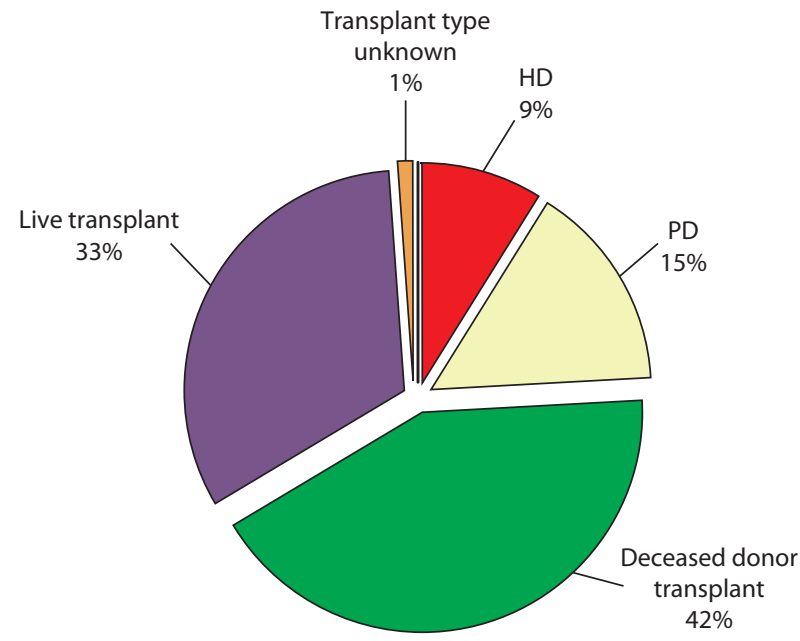

Fig. 5.1. RRT treatment used by prevalent paediatric patients $<16$ years old in 2010

\section{Modality of treatment}

Current treatment modality in the prevalent paediatric population less than 16 years old in 2010 is displayed in figure 5.1. Of the $76 \%$ with a functioning transplant, $56 \%$ of these were deceased donor transplantations.

The treatment modality in use at 90-days following commencement of RRT is displayed in figure 5.2. This shows that $53 \%$ of patients were treated with PD at 90 days whilst $21 \%$ of patients were treated with HD. Twenty-four percent of children under 16 were reported to have received a transplant either pre-emptively or by 90 days.

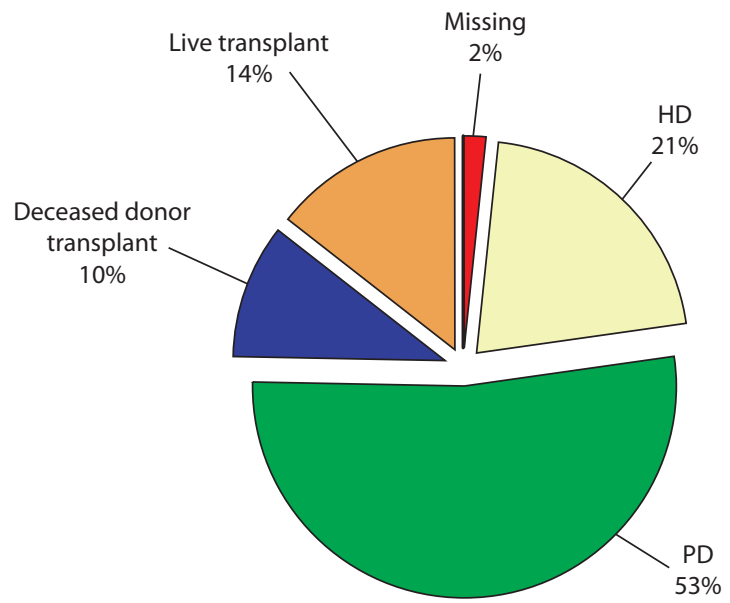

Fig. 5.2. Treatment modality at 90 days following commencement of RRT in prevalent paediatric patients under 16 years of age in 2010

Further treatment modality analysis by age is shown in table 5.4 which demonstrates that in the under 2 year olds the majority of patients were being treated with PD $(80 \%)$. This contrasts with older children in the 12 to 15.99 year age group where $84.6 \%$ had a functioning graft and where identical numbers were on $\mathrm{HD}$ and $\mathrm{PD}$ (7.7\%). Subsequent analysis of RRT modality by gender showed no difference. Similarly there was no difference in RRT modality when comparing different ethnic groups, though South Asian children had a trend for higher rates of deceased donor versus living donor transplantation when compared with White children $(\mathrm{p}=0.08)$.

Table 5.4. Current treatment modality by age in the prevalent paediatric ERF population in 2010

\begin{tabular}{|c|c|c|c|c|c|c|c|c|c|c|}
\hline \multirow[b]{3}{*}{ Age group } & \multicolumn{10}{|c|}{ Current treatment } \\
\hline & \multicolumn{2}{|c|}{ HD } & \multicolumn{2}{|c|}{$\mathrm{PD}$} & \multicolumn{2}{|c|}{ Live transplant } & \multicolumn{2}{|c|}{$\begin{array}{l}\text { Deceased donor } \\
\text { transplant }\end{array}$} & \multicolumn{2}{|c|}{$\begin{array}{c}\text { Transplant type } \\
\text { unknown }\end{array}$} \\
\hline & $\mathrm{N}$ & $\%$ & $\mathrm{~N}$ & $\%$ & $\mathrm{~N}$ & $\%$ & $\mathrm{~N}$ & $\%$ & $\mathrm{~N}$ & $\%$ \\
\hline 0-1.99 years & 3 & 12.0 & 20 & 80.0 & 2 & 8.0 & 0 & 0.0 & 0 & 0.0 \\
\hline $2-3.99$ years & 9 & 18.8 & 21 & 43.7 & 15 & 31.2 & 3 & 6.3 & 0 & 0.0 \\
\hline 4-7.99 years & 14 & 10.7 & 20 & 15.3 & 50 & 38.1 & 46 & 35.1 & 1 & 0.8 \\
\hline $8-11.99$ years & 12 & 6.9 & 20 & 11.5 & 49 & 28.2 & 89 & 51.1 & 4 & 2.3 \\
\hline $12-15.99$ years & 24 & 7.7 & 24 & 7.7 & 108 & 34.9 & 152 & 49.1 & 2 & 0.6 \\
\hline 16-17.99 years & 16 & 8.8 & 19 & 10.4 & 56 & 30.8 & 90 & 49.5 & 1 & 0.5 \\
\hline Under 16 years & 62 & 9.0 & 105 & 15.3 & 224 & 32.5 & 290 & 42.2 & 7 & 1.0 \\
\hline Under 18 years & 78 & 9.0 & 124 & 14.2 & 280 & 32.2 & 380 & 43.7 & 8 & 0.9 \\
\hline
\end{tabular}


Table 5.5. Number, percentage and gender by primary renal disease as cause of ERF in the prevalent paediatric ERF population under 16 years in 2010

\begin{tabular}{|c|c|c|c|c|c|}
\hline Diagnostic group & Total & $\%$ & Males & Females & $\mathrm{M}: \mathrm{F}$ ratio \\
\hline Obstructive uropathy & 119 & 17.3 & 109 & 10 & 10.9 \\
\hline Congenital nephrotic syndrome & 62 & 9.0 & 33 & 29 & 1.1 \\
\hline Tubulo-interstitial diseases & 43 & 6.3 & 19 & 24 & 0.8 \\
\hline Renovascular disease & 32 & 4.7 & 20 & 12 & 1.7 \\
\hline Polycystic kidney disease & 21 & 3.1 & 8 & 13 & 0.6 \\
\hline Malignancy \& associated disease & 16 & 2.3 & 5 & 11 & 0.5 \\
\hline Drug nephrotoxicity & 1 & 0.1 & 0 & 1 & 0.0 \\
\hline Missing & 20 & 2.9 & 13 & 7 & 1.9 \\
\hline
\end{tabular}

\section{Cause of ERF}

Table 5.5 and figure 5.3 show the diagnostic categories for the prevalent ERF population under 16 years in 2010 . There has been a marked improvement in data collection in this category with missing data falling from $15.5 \%$ of patients in the 2009 cohort to only $2.9 \%$ in 2010 . Of the 668 patients, renal dysplasia \pm reflux remained the commonest condition causing ERF (32.6\%), whilst drug nephrotoxicity was documented in only a single child.

As for associated comorbidities at the onset of RRT, table 5.6 shows that congenital abnormalities were the commonest, reported in $9 \%$ of patients, whilst both developmental delay and syndromic diagnoses were

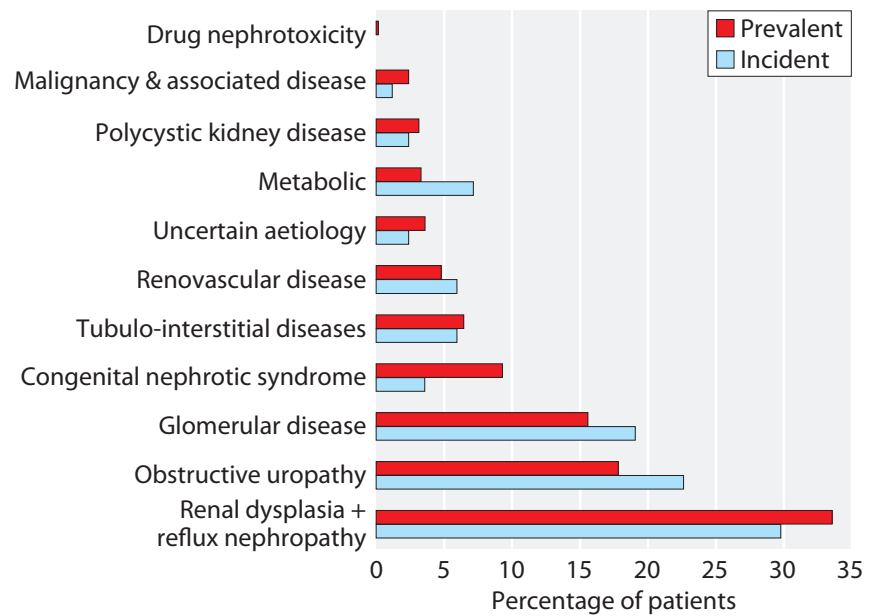

Fig. 5.3. Primary renal disease percentage in incident and prevalent paediatric ERF patients in 2010 for whom a causative diagnosis was reported reported in over 7\% of patients. Prematurity was also frequently reported $(7.6 \%)$, whilst neural tube defects were least common in $0.4 \%$ of patients. Overall $66.7 \%$ of patients had no registered comorbidities, with $22.2 \%$ having one comorbidity listed, and $11.1 \%$ having two or more comorbidities.

The UK incident paediatric ERF population in 2010

There were 106 patients under 18 years of age who commenced RRT at paediatric renal centres in 2010. As previously, the following analyses are restricted to the 94 patients who were under 16 years of age.

Table 5.6. Registered comorbidities at onset of RRT in prevalent paediatric patients with ERF in 2010

\begin{tabular}{lrc}
\hline Comorbidity & N & $\begin{array}{c}\text { Percentage all } \\
\text { RRT patients }\end{array}$ \\
\hline Cerebral palsy & 10 & 1.5 \\
Chromosomal abnormality & 21 & 3.1 \\
Congenital abnormality & 62 & 9.0 \\
Congenital heart disease & 15 & 2.2 \\
Consanguinity & 27 & 3.9 \\
Developmental delay & 53 & 7.7 \\
Diabetes & 2 & 0.3 \\
Liver disease & 11 & 1.6 \\
Malignancy & 8 & 1.2 \\
Neural tube defect & 3 & 0.4 \\
Family member with ERF & 19 & 2.8 \\
Prematurity & 52 & 7.6 \\
Psychological disorder & 8 & 1.2 \\
Syndromic diagnosis & 49 & 7.1 \\
No reported comorbidity & 459 & 66.7 \\
One reported comorbidity & 153 & 22.2 \\
Two or more reported comorbidities & 76 & 11.1 \\
\hline
\end{tabular}

Nephron Clin Pract 2012;120(suppl 1):c93-c103 
Table 5.7. The incident paediatric ERF population in the UK in 2010, by age group and gender

\begin{tabular}{|c|c|c|c|c|c|c|c|}
\hline \multirow[b]{2}{*}{ Age group } & \multicolumn{2}{|c|}{ All patients } & \multicolumn{2}{|c|}{ Males } & \multicolumn{2}{|c|}{ Females } & \multirow[b]{2}{*}{$\mathrm{M}: \mathrm{F}$ ratio } \\
\hline & $\mathrm{N}$ & pmarp & $\mathrm{N}$ & pmarp & $\mathrm{N}$ & pmarp & \\
\hline $0-1.99$ years & 21 & 13.3 & 16 & 19.8 & 5 & 6.5 & 3.0 \\
\hline $2-3.99$ years & 10 & 6.5 & 4 & 5.1 & 6 & 8.0 & 0.6 \\
\hline $4-7.99$ years & 16 & 5.6 & 9 & 6.2 & 7 & 5.0 & 1.2 \\
\hline $8-11.99$ years & 16 & 5.9 & 6 & 4.3 & 10 & 7.5 & 0.6 \\
\hline $12-15.99$ years & 31 & 10.6 & 18 & 12.0 & 13 & 9.1 & 1.3 \\
\hline Under 16 years & 94 & 8.1 & 53 & 8.9 & 41 & 7.2 & 1.2 \\
\hline
\end{tabular}

pmarp - per million age related population

The incidence rate of RRT was 8.1 pmarp in 2010. These patients commencing RRT in 2010 are displayed by age and gender in table 5.7 .

Table 5.8 shows that the reported incidence of RRT has been rising since 1996, with the highest incidence rates seen in the 12-15.99 year age group, with the $0-1.99$ year age group having the next highest rates.

\section{Trends in ERF demographics}

Analysis of ERF demographics for children less than 16 years of age over the past 15 years confirmed that

Table 5.8. Reported average incident rate by age group, in 5year time periods, of children under 16 years of age commencing RRT

\begin{tabular}{lccc}
\hline & \multicolumn{3}{c}{ Per million age related population } \\
\cline { 2 - 4 } Age group & $1996-2000$ & $2001-2005$ & $2006-2010$ \\
\hline $0-1.99$ years & 9.9 & 13.6 & 13.5 \\
2-3.99 years & 6.2 & 5.7 & 7.6 \\
4-7.99 years & 4.9 & 6.2 & 6.6 \\
8-11.99 years & 7.9 & 8.2 & 8.8 \\
12-15.99 years & 13.3 & 13.1 & 14.6 \\
Under 16 years & $\mathbf{8 . 5}$ & $\mathbf{9 . 4}$ & $\mathbf{1 0 . 3}$ \\
\hline
\end{tabular}

there were 512 patients reported to the paediatric registry between 1996-2000, 548 between 2001-2005 and 591 between 2006-2010. Comparing the current 5 year period with the previous 5 year periods there has been an overall increase in the number of children treated with RRT, particularly in children aged 0 to 1.99 years (table 5.9). The percentage of children on RRT who are from South Asian or Black ethnic backgrounds has also increased during this period (table 5.10). The reported patient population at most paediatric renal centres has similarly grown in size since 1996-2000 with Belfast and Birmingham showing the largest proportional rises (table 5.11).

Table 5.12 shows the number and percentage of children receiving RRT with each of the major reported comorbidities over the last 15 years. Whilst congenital abnormalities (8.6\%), developmental delay $(7.1 \%)$ and syndromic diagnoses $(6.8 \%)$ were the most common reported comorbidities in 2006-2010, there has been little change in the percentage of children receiving RRT with a reported comorbidity over the last 15 years.

As for changes in modality at day 90 after starting RRT, figure 5.4 shows that the percentage of children who were using $\mathrm{PD}$ at 90 days has fallen slightly from $48.7 \%$ in $1996-2000$ to $46.8 \%$ in $2006-2010$ whilst the

Table 5.9. Number and percentage of children who commenced RRT, by age group and 5 year period

\begin{tabular}{|c|c|c|c|c|c|c|c|}
\hline \multirow[b]{2}{*}{ Age group } & \multicolumn{2}{|c|}{ 1996-2000 } & \multicolumn{2}{|c|}{ 2001-2005 } & \multicolumn{2}{|c|}{ 2006-2010 } & \multirow{2}{*}{$\begin{array}{l}\text { 1996-2010 } \\
\text { \% change }\end{array}$} \\
\hline & $\mathrm{N}$ & $\%$ & $\mathrm{~N}$ & $\%$ & $\mathrm{~N}$ & $\%$ & \\
\hline $0-1.99$ years & 70 & 13.7 & 91 & 16.6 & 104 & 17.6 & 3.9 \\
\hline $2-3.99$ years & 45 & 8.8 & 38 & 6.9 & 55 & 9.3 & 0.5 \\
\hline 4-7.99 years & 74 & 14.5 & 89 & 16.2 & 90 & 15.2 & 0.8 \\
\hline $8-11.99$ years & 123 & 24.0 & 124 & 22.6 & 125 & 21.2 & -2.9 \\
\hline $12-15.99$ years & 200 & 39.1 & 206 & 37.6 & 217 & 36.7 & -2.3 \\
\hline under 16 years & 512 & & 548 & & 591 & & \\
\hline
\end{tabular}


Table 5.10. Number and percentage of children under 16 years who commenced RRT, by ethnicity and 5 year period of starting RRT

\begin{tabular}{|c|c|c|c|c|c|c|c|}
\hline \multirow[b]{2}{*}{ Ethnic group } & \multicolumn{2}{|c|}{ 1996-2000 } & \multicolumn{2}{|c|}{ 2001-2005 } & \multicolumn{2}{|c|}{ 2006-2010 } & \multirow{2}{*}{$\begin{array}{l}\text { 1996-2010 } \\
\% \text { change }\end{array}$} \\
\hline & $\mathrm{N}$ & $\%$ & $\mathrm{~N}$ & $\%$ & $\mathrm{~N}$ & $\%$ & \\
\hline S Asian & 78 & 15.4 & 81 & 15.1 & 90 & 16.0 & 0.6 \\
\hline Black & 11 & 2.2 & 12 & 2.2 & 20 & 3.6 & 1.4 \\
\hline Other & 17 & 3.4 & 22 & 4.1 & 27 & 4.8 & 1.5 \\
\hline
\end{tabular}

* There were 6 children in 1996-2000, 11 in 2001-2005 and 30 in 2006-2010 with no ethnicity recorded and these are not included in this table

Table 5.11. Number and percentage of children under 16 years reported to the UKRR, by renal centre and 5 year period ${ }^{*}$

\begin{tabular}{|c|c|c|c|c|c|c|c|}
\hline \multirow[b]{2}{*}{ Centre } & \multicolumn{2}{|c|}{ 1996-2000 } & \multicolumn{2}{|c|}{ 2001-2005 } & \multicolumn{2}{|c|}{ 2006-2010 } & \multirow{2}{*}{$\begin{array}{l}\text { 1996-2010 } \\
\% \text { change }\end{array}$} \\
\hline & $\mathrm{N}$ & $\%$ & $\mathrm{~N}$ & $\%$ & $\mathrm{~N}$ & $\%$ & \\
\hline Blfst_P & 14 & 2.8 & 17 & 3.1 & 27 & 4.6 & 1.8 \\
\hline Bham_P & 41 & 8.1 & 55 & 10.1 & 62 & 10.5 & 2.4 \\
\hline Brstl_P & 35 & 6.9 & 44 & 8.0 & 34 & 5.8 & -1.1 \\
\hline Cardf_P & 15 & 2.9 & 17 & 3.1 & 17 & 2.9 & -0.1 \\
\hline Glasg_P & 39 & 7.7 & 31 & 5.7 & 43 & 7.3 & -0.4 \\
\hline L Eve_P & 54 & 10.6 & 45 & 8.2 & 63 & 10.7 & 0.1 \\
\hline L GOS̄H_P & 97 & 19.1 & 98 & 17.9 & 117 & 19.8 & 0.7 \\
\hline Leeds_P & 40 & 7.9 & 49 & 9.0 & 54 & 9.1 & 1.3 \\
\hline Livpl_P & 23 & 4.5 & 31 & 5.7 & 19 & 3.2 & -1.3 \\
\hline Manch_P & 51 & 10.0 & 53 & 9.7 & 45 & 7.6 & -2.4 \\
\hline Newc_P & 28 & 5.5 & 32 & 5.9 & 27 & 4.6 & -0.9 \\
\hline Nottm_P & 58 & 11.4 & 48 & 8.8 & 66 & 11.2 & -0.2 \\
\hline Soton_P & 14 & 2.8 & 27 & 4.9 & 17 & 2.9 & 0.1 \\
\hline Total $<16$ & 509 & & 547 & & 591 & & \\
\hline
\end{tabular}

* There were 3 children in 1996-2000 and 1 in 2001-2005 with unknown centre of RRT start and these are not included in this table

Table 5.12. Trends in comorbidity at the start of RRT in the paediatric population under 16 years, by 5 year period

\begin{tabular}{|c|c|c|c|c|c|c|c|}
\hline \multirow[b]{2}{*}{ Comorbidity } & \multicolumn{2}{|c|}{ 1996-2000 } & \multicolumn{2}{|c|}{ 2001-2005 } & \multicolumn{2}{|c|}{ 2006-2010 } & \multirow{2}{*}{$\begin{array}{l}\text { 1996-2010 } \\
\% \text { change }\end{array}$} \\
\hline & $\mathrm{N}$ & $\%$ & $\mathrm{~N}$ & $\%$ & $\mathrm{~N}$ & $\%$ & \\
\hline Chromosomal abnormality & 14 & 2.7 & 13 & 2.4 & 18 & 3.1 & 0.3 \\
\hline Congenital abnormality & 31 & 6.1 & 50 & 9.1 & 51 & 8.6 & 2.6 \\
\hline Congenital heart disease & 14 & 2.7 & 12 & 2.2 & 18 & 3.1 & 0.3 \\
\hline Diabetes & 4 & 0.8 & 5 & 0.9 & 2 & 0.3 & -0.4 \\
\hline Liver disease & 0 & 0.0 & 9 & 1.6 & 11 & 1.9 & 1.9 \\
\hline Malignancy & 9 & 1.8 & 8 & 1.5 & 2 & 0.3 & -1.4 \\
\hline Neural tube defect & 3 & 0.6 & 3 & 0.6 & 3 & 0.5 & -0.1 \\
\hline Family member with ERF & 24 & 4.7 & 20 & 3.7 & 10 & 1.7 & -3.0 \\
\hline Prematurity & 31 & 6.1 & 27 & 4.9 & 29 & 4.9 & -1.1 \\
\hline One reported comorbidity & 97 & 19 & 147 & 26.8 & 109 & 18.4 & -0.6 \\
\hline Two or more reported comorbidities & 65 & 13 & 54 & 9.9 & 57 & 9.6 & -3.4 \\
\hline
\end{tabular}




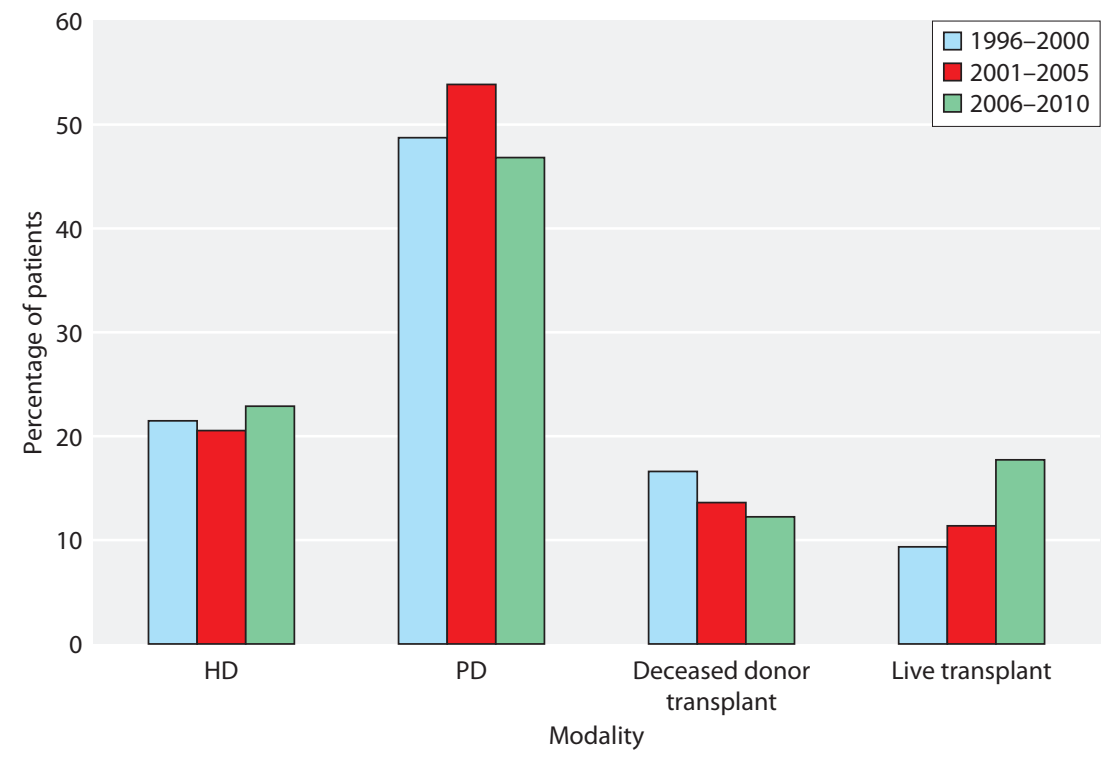

Fig. 5.4. Treatment modality at day 90 after starting RRT by 5 year time period percentage commencing RRT on HD has increased from $21.5 \%$ in $1996-2000$ to $22.9 \%$ in $2006-2010$. During this period the overall percentage receiving a transplant before 90 days has remained largely unchanged though living donation has risen from $9.4 \%$ in 1996-2000 to $17.7 \%$ in 2006-2010, with a corresponding fall in deceased donor transplantation from $16.6 \%$ to $12.2 \%$ for the same time period.

Table 5.13 shows the diagnostic categories for 493 of the $512(96.3 \%)$ patients in 1996-2000, for 523 of the $548(95.4 \%)$ patients in 2001-2005 and 550 of the 591 (93.1\%) patients in 2006-2010 aged $<16$ years for whom a causative diagnosis was reported.
Overall there has been an increase in the percentage of children receiving RRT with unknown aetiology between 1996-2000 and 2006-2010 (2.2\% vs. 5.1\%) and a decrease in metabolic diseases $(5.9 \%$ vs. $4.5 \%)$ though absolute numbers are very small (table 5.13).

\section{Transfer of patients to adult renal services in 2010}

A total of 73 patients were reported by paediatric nephrology centres to have been transferred to adult renal services in 2010. The median age of patients transferred out was 18.0 years with a range of 16.1 years to 20.1 years. As expected the largest numbers of

Table 5.13. Number and percentage of children under 16 years for whom a primary renal diagnosis had been reported as a cause of ERF, by 5 year time period along with observed change in proportion of patients in each diagnostic group ${ }^{*}$

\begin{tabular}{|c|c|c|c|c|c|c|c|}
\hline \multirow[b]{2}{*}{ Primary renal diagnosis } & \multicolumn{2}{|c|}{ 1996-2000 } & \multicolumn{2}{|c|}{ 2001-2005 } & \multicolumn{2}{|c|}{ 2006-2010 } & \multirow{2}{*}{$\begin{array}{l}\text { 1996-2010 } \\
\text { \% change }\end{array}$} \\
\hline & $\mathrm{N}$ & $\%$ & $\mathrm{~N}$ & $\%$ & $\mathrm{~N}$ & $\%$ & \\
\hline Renal dysplasia \pm reflux & 163 & 33.1 & 172 & 32.9 & 176 & 32.0 & -1.1 \\
\hline Obstructive uropathy & 77 & 15.6 & 78 & 14.9 & 89 & 16.2 & 0.6 \\
\hline Glomerular disease & 103 & 20.9 & 110 & 21.0 & 114 & 20.7 & -0.2 \\
\hline Congenital nephrotic syndrome & 28 & 5.7 & 29 & 5.5 & 29 & 5.3 & -0.4 \\
\hline Tubulo-interstitial diseases & 37 & 7.5 & 42 & 8.0 & 41 & 7.5 & -0.1 \\
\hline Renovascular disease & 18 & 3.7 & 18 & 3.4 & 21 & 3.8 & 0.2 \\
\hline Uncertain aetiology & 11 & 2.2 & 19 & 3.6 & 28 & 5.1 & 2.9 \\
\hline Metabolic & 29 & 5.9 & 23 & 4.4 & 25 & 4.5 & -1.3 \\
\hline Polycystic kidney disease & 14 & 2.8 & 13 & 2.5 & 16 & 2.9 & 0.1 \\
\hline Malignancy \& associated disease & 5 & 1.0 & 10 & 1.9 & 8 & 1.5 & 0.4 \\
\hline Drug nephrotoxicity & 8 & 1.6 & 9 & 1.7 & 3 & 0.5 & -1.1 \\
\hline
\end{tabular}

* There were 19 children in 1996-2000, 25 in 2001-2005 and 41 in 2006-2010 with no PRD recorded and these are not included in this table 
Table 5.14. Modality, gender, ethnicity and primary renal diagnosis of patients transferred out of paediatric nephrology centres in 2010

\begin{tabular}{lcc}
\hline & N & $\begin{array}{c}\% \\
\text { distribution }\end{array}$ \\
\hline Modality & 7 & \\
HD & 4 & 9.6 \\
PD & 62 & 84.5 \\
Transplant & & \\
Gender & 33 & 45.2 \\
Female & 40 & 54.8 \\
Male & & \\
Ethnicity & & \\
Black & 2 & 2.8 \\
Asian & 10 & 13.9 \\
White & 60 & 83.3 \\
Primary Renal Diagnosis & \\
Renal dysplasia \pm reflux & & \\
Obstructive uropathy & 23 & 32.9 \\
Glomerular disease & 8 & 11.4 \\
Tubulo-interstitial diseases & 14 & 20 \\
Renovascular disease & 6 & 8.6 \\
Uncertain aetiology & 2 & 2.9 \\
Metabolic & 6.6 \\
Polycystic kidney disease & 6 & 5.7 \\
Congenital nephrotic syndrome & 4 & 2.9 \\
* & 5 & 7.1 \\
\hline
\end{tabular}

* ethnicity missing in 1 patient, and PRD missing in 3 patients

adolescents transferred to adult services were from the centres with the largest cohort of patients with ERF.

Table 15.14 shows that of the transferred patients $54.8 \%$ were male, with ethnic minorities constituting $16.7 \%$ of patients. The vast majority $(84.9 \%)$ had a functioning renal transplant at the time of transfer to an adult renal centre. Renal dysplasia \pm reflux was the primary renal diagnosis in nearly a third of patients.

\section{Mortality data in 2010}

There were seven deaths in renal paediatric centres in 2010. The reported mortality of children with treated ERF in 2010 in the UK was 1\% (7/688). The median age at death was 1.2 years (range: 0.2 years to 15.5 years) and 57\% were less than 16 months old. Sepsis was cited as a cause of death in two patients on dialysis, and one patient died after developing cardiac complications after undergoing bilateral nephrectomies. In four children the cause of death was related to opting for withdrawing from dialysis and receiving palliative care following a combination of reasons including failure of transplant, cerebrovascular accident or complications related to dialysis.

\section{Discussion}

This report from the Paediatric Renal Registry has focussed on the description of the current demography and the demographic trends over the past 15 years of the UK paediatric ERF population. Over the past few years a sustained effort has been made by the members of the BAPN and the Paediatric renal registry subcommittee to improve data quality by:

(i) involving a data manager and a statistician as well as paediatric nephrologists in the team processing the data

(ii) merging all available datasets into the larger adult UKRR database and

(iii) aiming to have electronic annual returns from all paediatric centres.

On this background of continuing 'process transition', $87.5 \%(602 / 688)$ of patients from 10 of 13 paediatric nephrology centres had their data submitted electronically. This report focuses on 688 children and adolescents $<16$ years of age, who were receiving RRT in 2010 . The sub-section on the trends in demographics includes 512 from 1996-2000, 548 from 2001-2005 and 591 from 2006-2010 children and adolescents $<16$ years of age on RRT.

\section{Completeness of data}

As shown in table 5.1, completeness of data was $>90 \%$ for key variables with the exception of two, height or length at start of RRT and plasma creatinine at start of RRT had lower completion rates at $75.5 \%$ and $82 \%$ respectively. This is an improvement from last year's report and reflects results of ongoing efforts within the UKRR to complete missing key data variables. The authors hope to continue to make steady progress with this in future reports.

\section{Incidence, prevalence and trends}

As shown in table 5.7, the incident paediatric ERF population $<16$ years of age is lower at 8.1 pmarp than that reported last year [1]. This is probably a result of merging of databases and removal of inaccuracies within the database. Reviewing trends in incidence rates over the past 15 years suggests fluctuations from 
year to year but a significant increase in average 5-year incident rates during this time period (table 5.8). Although yearly fluctuation has been described in reports from other renal registries [3] the increasing trend in average 5-year incidence rates of children on RRT is in keeping with our observations last year [1].

Analysis of the incidence rates in different age bands as displayed in table 5.8 suggests this has been maximal in the 12-15.99 year age band followed by the $0-1.99$ year age band. A possible explanation for these observed demographic trends is that a greater proportion of children and adolescents $<16$ years now receive their RRT at paediatric nephrology centres only and that an increasing number of infants and young children are being considered for RRT as a result of improvements in techniques to provide nutritional support and dialysis therapy in this cohort.

The prevalence of children on RRT as shown in table 5.2 increased with age in keeping with improved survival with increasing age. This coupled with an increase in the number of children receiving RRT over the past 15 years has led to a steady increase in the prevalent ERF population (table 5.9). This trend has been observed nationally and across most paediatric nephrology centres (table 5.11). Factors underlying the centre variation seen in the rise in reported patient numbers over time may include variations in the incidence of renal disease related to changes in ethnicity of the local population and variations in the systems in place to support data collection.

\section{Treatment modality of ERF and observed trends 1996-2010}

The majority of prevalent children (76\%) on RRT have functioning transplants with a steady increase in prevalent children with a functioning transplant seen over the past 15 years (data not shown).

In 2010, the treatment modality at 90 days for peritoneal dialysis was 53\%, haemodialysis $21 \%$ and transplantation at 24\% (figure 5.2). Analysis of these trends in 'modality at 90 days' over the past 15-years (figure 5.4) shows that whilst there has been a modest rise overall in the proportion of patients who have commenced RRT with transplantation (26.0\% in 1996-2000 to $29.9 \%$ in 2005-2009), living donation has shown the greatest rise of $8.3 \%$ (from $9.4 \%$ in 1996-2000 to $17.7 \%$ in 2006-2010). This near doubling of living donation rates over the past 15 years is obviously welcome news given the well documented advantages of living versus deceased donor renal transplantation.
The reasons for the continued high prevalence rates of dialysis as treatment modality at 90 days are complex and it can only be speculated on the possible reasons for the findings here. As discussed previously [1], these reasons may include the increasing incidence of ERF in the youngest patients ( $<4$ years of age) who are commencing RRT (table 5.9) and in whom dialysis often is the only possible modality, increasing incidence in ethnic minorities now commencing RRT (table 5.10) and in whom rates of live-donor transplantation remain low [4] and possible paediatric specific reasons including associated comorbidities, family and social issues for which there is little information but would benefit from more detailed review.

\section{Comorbidities}

Comorbidities have been reported as previously with the addition of an analysis showing the percentage of children with no, one or two reported comorbidities. This may be helpful in better understanding the burden of disease faced by the patients, their families and the professionals looking after them.

\section{Causes of ERF and observed trends 1996-2010}

Overall, renal dysplasia \pm reflux at $32.6 \%$, glomerulonephritis at $15.1 \%$ and obstructive uropathy at $17.3 \%$ were the commonest listed aetiologies for children with ERF, these accounted for $65 \%$ of all patients for whom a primary diagnosis had been reported. Renal dysplasia \pm reflux and obstructive uropathy were both more common in males with a male:female ratio of $2: 1$ and 11:1 respectively. Observation of trends over the 15year period showed an increase in the percentage of children receiving RRT with unknown aetiology between 1996-2000 and 2006-2010 (2.2\% vs. 5.1\%), and a decrease in metabolic diseases (5.9\% vs. $4.5 \%)$ although absolute numbers remained small making it difficult to analyse possible reasons (table 5.13).

\section{Transfer out and mortality in 2010}

In this report for the first time, data are reported on the transfer of adolescents and young adults with childhood onset ERF to adult renal centres across the UK. Seventy three young adults transferred from paediatric to adult renal centres in 2010. The median age at transfer was 18 years with a range of 16.1 to 20.1 years. This may reflect patient choice or differing policies for transition and transfer. There is increasing recognition of the specific needs of this age group and further work in this area is in progress. 
The incident mortality rate in 'childhood onset' ERF during childhood at $1 \%$ underscores the 'high-risk' nature of this population with the underlying cause of death in these children reflecting the practical issues involved in managing them.

With the ongoing merger of the UKRR adult and paediatric databases, future reports will provide greater detail regarding this cohort and lead to important outcome including survival data in this population. The authors also hope that inclusion of this data in future reports will improve reporting by individual centres.

Conflicts of interest: none

\section{References}

1 Sinha MD, Castledine C, van Schalkwyk D, Farida Hussain F, Lewis M, Inward C. UK Renal Registry 13th Annual Report (December 2010): Chapter 5 Demography of the UK Paediatric Renal Replacement Therapy Population in 2009. Nephron Clin Pract 2011;119(suppl 2):c97-c106. DOI: $10.1159 / 000331755$

2 http://www.Ons.Gov.Uk/census

3 McTaggart S, Dent H, Kennedy S, Johnstone L, McDonald S. Chapter 11 Paediatric Report. ANZDATA Registry Report 2010, Australia and New Zealand Dialysis and Transplant Registry, Adelaide, South Australia
4 Lewis MA, Shaw J, Sinha MD, Adalat S, Hussain F, Castledine C, Schalkwyk DV, Inward C. UK Renal Registry 12th Annual Report (December 2009): Chapter 14 Demography of the UK Paediatric Renal Replacement Therapy population in 2008. Nephron Clin Pract 2010; 115(suppl 1):c279-c288 